\title{
THE WARD SISTER AS A HEALTH EDUCATOR
}

\section{Woodward, B.A., RGN, RM, D.N.Ed.}

According to Thomson ${ }^{(1)}$, hospital patients form a target group of particular importance for the health educator because

- the patients suffering from a particular disease are a motivated group so far as education related to their illness is concerned, and

- hospital patients are restricted to a certain environment for comparatively long periods of time in many instances, and thus represent a captive group for health education.

To fulfil her function as a health educator, and to exploit the full potential of this captive audience, I believe the ward sister could usefully consider the education of her patients under two main headings:

- education for healthy living irrespective of diagnosis, and

- education which will enable a patient to maintain health outside the hospital despite the diagnosis.

Taking the first category, obviously it is impracticable (and inadvisable) to provide every patient with a full course of learning experiences in all aspects of health maintenance. However, depending on the type of ward, and the probable interests of the average patient in such a ward, a simple programme could be prepared and introduced in group- or individual- discussions with patients. Examples of topics which readily spring to mind include

- in a gynaecological ward

- breast examination

- warning signs of genital carcinoma

- venereal diseases

- family planning

- mothers in a paediatric ward

- family nutrition

- budgetting

- hygiene

- home management of minor ailments

- prevention of home accidents

- in a male medical ward

- cigarette smoking and associated dangers
- exercise for health

- family planning!

In the second category, the needs of individual patients for education will vary according to diagnosis, ability to assimilate new information and develop new skills. It is essential here to establish the patient's needs and to plan to meet them, using the steps of the nursing process - assess, plan, implement, evaluate. A standard guide related to each common diagnosis could be used to help establish problem areas, but the action planned must meet individual needs and capabilities which presupposes the setting of realistic objective for each step.

A condition which requires extensive education of the patient and his family is diabetes mellitus, where the patient's ability to maintain health outside the hospital is often directly proportional to the excellence of his education for this. Such education must extend beyond the time-honoured triad of urine-testing, insulin dosage and administration, and diet, to embrace teaching of foot care, skin hygiene, planning for additional energy expenditure, signs of complications and what to do about these, and so on. A patient with diabetes mellitus should not be discharged until the ward sister is able to assure the physician that his patient is able to care for himself safely at home.

Patients with many other conditions have a need for similar planned programmes of education - the patient with hemiplegia or paraplegia, the arthritic patient, the patient who has recovered from a myocardial infarction. So often it is not the big issues in home care which represent the major problems for the patient and his family - it is the small, unconsidered difficulties which perhaps only the ward sister with her unique knowledge and skill as a nurse may suspect, which will make all the difference in ensuring a secure and comfortable adjustment to life outside the hospital.

\section{Reference:}

Thomson, William: Health Education - 4: Whom Do We Educate?; Nursing Times, Vol. 74, No. 40, 5.10.1978. 